\title{
EFEITOS MATERNOS E NEONATAIS DA TERAPIA ANTIRRETROVIRAL COM EFAVIRENZ EM GESTANTES PORTADORAS DO VÍRUS DA IMUNODEFICIÊNCIA HUMANA
}

\author{
Helena Barbi , Helaine Maria Besteti Pires Mayer Milanez, Anderson Adriano L. F. da Costa
}

\begin{abstract}
Resumo
Foi realizado um estudo observacional, de coorte, retrospectivo e analisados dados referentes às gestantes atendidas no ambulatório especializado em HIV e gestação, e que foram expostas à TARV contendo Efavirenz, e seus respectivos recém nascidos, no período entre 2000 e 2019. Variáveis maternas incluiram idade, escolaridade, cor, estado civil, antecedentes obstétricos; anemia, alteração de função hepática e renal; plaquetopenia; hiperglicemia; reação alérgica; dislipidemia e patologias associadas ou comorbidades. Com relação ao recém-nascido, foram analisadas as variáveis: peso, comprimento, APGAR, CAPURRO; adequação de peso à idade gestacional; anemia; alteração de função hepática; plaquetopenia; malformações e intercorrências neonatais.
\end{abstract}

\section{Palavras-chave:}

Antirretroviral, gestantes, efavirenz.

\section{Introdução}

Atualmente, aproximadamente 38,8 milhões de pessoas no mundo são infectadas pelo Vírus da Imunodeficiência Humana (HIV), sendo quase $50 \%$ mulheres, a maior parte delas em idade reprodutiva, o que pode impactar no risco de transmissão vertical, já que ao redor de $80 \%$ das crianças infectadas contraíram a doença durante a vida intrauterina.O principal fator associado à TV é a carga viral materna. A TARV é a medida mais eficiente de controle da carga viral (CV). Ainda hoje faltam dados absolutos sobre os diferentes efeitos adversos da TARV em gestantes e seus recem nascidos expostos.

O objetivo desse estudo é avaliar os efeitos adversos da TARV contendo Efavirenz em seu esquema, tanto de gestantes quanto de seus respectivos recém-nascidos.

\section{Resultados e Discussão}

Foram avaliados 112 prontuários até o momento, de pacientes do CAISM-UNICAMP, gestantes, HIV positivas e que foram expostas ao Efavirenz em seu esquema TARV, tendo o parto realizado em nosso serviço entre os anos de 2000 e 2019. Foram analisados variáveis maternas e neonatais, e preenchido uma tabela contendo todas as informações presentes tanto nos prontuários físicos quanto eletrônicos. Dentre as variáveis maternas destaca-se: idade, número de consultas de pré-natal, ganho de peso durante a gestação, CD4 e carga viral, hemoglobina, plaquetas, enzimas hepáticas, glicemia e colesteróis. Dentre as variáveis neonatais destaca-se: peso ao nascer, comprimento, índice de APGAR (10 e $5^{\circ}$ minuto), hemoglobina, plaquetas, enzimas hepáticas e glicemia.

Foi então realizada uma média entre os valores obtidos nos prontuários, e até 0 momento temos como resultados maternos: a idade média foi de 31,3 anos; o número de consulta de pré-natal médio foi de 8,5 ; o ganho de peso durante a gestação médio foi de $10,3 \mathrm{~kg}$; taxa CD4 média foi de 644; foi percebida uma porcentagem de $28,6 \%$ de anemia materna; de $7,1 \%$ de plaquetopenia, de $30,4 \%$ de alteração de enzimas hepáticas; de $49 \%$ de dislipidemia, e 18,8\% de alteração glicêmica. Já nas análises dos dados neonatais temos como resultados até o momento: o peso ao nascer médio foi de $2680 \mathrm{~g}$; o comprimento médio foi de 45,9 $\mathrm{cm}$; o APGAR de $1^{\circ}$ minuto médio foi de 8,4 e o de $5^{\circ}$, de 9,5; a porcentagem de recém-nascidos com anemia foi de $17,9 \%$; de plaquetopenia, $2,7 \%$; de alterações hepáticas, $17 \%$. Além disso, a porcentagem de abortamento foi de $3,6 \%$, e de óbito fetal foi de $0,9 \%$. Dentre as gestações, $22,3 \%$ apresentou algum tipo de complicação durante a gestação (ex. alteração de líquido amniótico, restrição de crescimento intrauterino, quadro gripal). Também foi visto uma porcentagem de $9,7 \%$ de malformações congênitas, entre elas macrocrania, atrésia de esôfago, duplicidade ureteral incompleta.

\section{Conclusões}

Visto que ainda estão sendo coletados dados presentes nos prontuários, e que algumas gestações ainda não tiveram desfecho; ainda não dispomos de todos os resultados que procuramos. Assim, nos resta finalizar a coleta de dados, e realizar as médias e frequências para dispormos de uma análise qualitativa e quantitativamente mais fidedigna da realidade; $e$ portanto, avaliar com mais eficiência os efeitos maternos e neonatais da terapia antirretroviral contendo Efavirenz.

${ }^{1}$ DE RUITER, A.; TAYLOR, G. P.; CLAYDEN, P. et al BRITISH HIV ASSOCIATION GUIDELINES for the management of HIV infection in pregnant women 2012 (2014 interim review). HIV medicine, [S.I.], v. 15, supl. 4, p. 1-77,

set. 2014.

${ }^{2}$ Declaração de Helsinque. Sobre os Princípios Éticos para Pesquisas em seres humanos. 64A. Assembléia Geral da WMA. Fortaleza, Brasil, 2013.

${ }^{3}$ BRASIL. Ministério da Saúde. Secretaria de Projetos Especiais de Saúde.

Coordenação Nacional de DST/AIDS. Boletim Epidemiológico AIDS/DST. Brasília, Dezembro, 2005. 